\title{
IMPRINTINNG, HONEYMOONING, OR MATURING: \\ Testing Three Theories of How Interfirm Social Bonding Impacts \\ Suppliers' Allocations of Resources to Business Customers
}

Arch G. Woodside, Boston College

Roger Baxter, Auckland Universit of Technology

Send correspondence to Arch G. Woodside, Boston College, Carroll School of Management, Department of Marketing, 140 Commonwealth Avenue, Chestnut Hill, MA 02467 USA; telephone/fax: 1-617 552-3069/6677, arch.woodside@ bc.edu.

Full reference: Woodside, A. and Baxter, R. 2015. Imprinting, honeymooning, or maturing: Testing three theories of how interfirm social bonding impacts suppliers' allocations of resources to business customers. Australasian Marketing Journal, 23 (2): pp. 96-106. 


\begin{abstract}

\section{Purpose}

This paper addresses two key questions about the effect of social bonds on the way in which a supplier allocates resources to its relationship with a buyer. In business markets, does strength of social bonds that a supplier perceives with a specific customer influence the supplier's allocations of resources relative to other customers? If social bonding does uniquely impact supplier allocation of resources to customers, does the impact vary by relationship duration?

\section{Design}

The study here tests three alternative theories of how interfirm social bonds impact suppliers' allocations of resources to customers: imprinting; honeymooning, and maturing. Imprinting theory suggests that first impressions support long-term favorable influences. Honeymooning theory suggests favorable first impressions end later with negative impacts. Maturing suggests a positive social by time interaction impact.

\title{
Findings
}

Analysis of data from sales and marketing managers confirms that two of these models of the impact of social bonding on supplier resource allocation, the imprinting theory and the maturity theory, are relevant. The findings indicate that the maturity and imprinting models of social bonding's influence on supplier resource allocations are more germane than the honeymoon model to interfirm relationship management.

\section{Implications}


The findings indicate that relationship managers need to take into account the clear effect that creation of strong social bonds in buyer-seller relationships, as distinct from financial bonds, has on the way in which suppliers allocate resources to those relationships and how relationship duration affects the way in which they do so.

\section{Originality/value}

The study tests research questions which are apparently heretofore untested in the extant literature and the study does so based on quantitative data rather than the qualitative data frequently used in this type of research. The study strengthens the argument, on a strong theoretical base, to adopt a collaborative, as opposed to a transactional, approach to interfirm buyer-seller relationships.

Keywords: Relationship; financial bond; resource allocation; social bond 


\section{INTRODUCTION}

This article empirically investigates social behavior influences in interfirm buyerseller relationships. In order to explain the interplay between social bonds and interfirm resource allocations, the article uses sociological concepts and propositions in combination with other relationship marketing concepts (cf. Blau, 1964; Håkansson, 1982; Kelley \& Thibaut, 1978; Macneil, 1980; Vargo \& Lusch, 2004). The study specifically investigates two research questions. In business markets, does strength of social bonds that a supplier perceives with a specific customer, independently of financial bonds, influence the supplier's allocations of financial, physical, time, and intangible resources to this customer relative to other customers? If social bonding does uniquely independent impact supplier allocation of resources to customers, how does the impact vary over the duration of the supplier-customer social relationship? Theory indicates that empirical research would affirm a positive answer to the first question and substantial variance in resource allocation due to the duration executives in interfirm social relationships. Questions such as these become important because they relate to the growing interest in mobilization of resources by actors in buyerseller relationships (Cantù, Corsaro, \& Snehota, 2012) and interest in customer attractiveness (Baxter, 2012; Schiele, Calvi, \& Gibbert, 2012).

This introduction identifies the key variables of the study, which are social bonds, resources allocated to relationships, and time. Section two of the article presents a review of theory and literature relevant to the link between relationship bonds and resource allocation. Section two also includes formal statements of alternative models of the impact of social bonds on supplier (or customer) allocations of resources and relevant hypotheses. Section three describes the method for examining the models empirically. Section four presents the findings from the study. Section five discusses implications for theory and managing 
relationships among suppliers and business customers. Section six discusses limitations. Section seven offers conclusions and suggestions for future research.

\section{THEORY DEVELOPMENT}

\subsection{Theory and research on social bonds among suppliers and business customers}

The concept of reciprocity of resource exchange in sociological exchanges (e.g. Blau, 1964; Gouldner, 1960), in adaptations made by business partners generally (e.g. Williamson, 1975; 1984), and in marketing relationships specifically (Bagozzi, 1995), has led to studies showing that high reciprocity frequency in business-to-consumer marketing contexts. The studies show customer loyalty resulting reciprocally from supplier resource inputs (e.g. De Wulf, Odekerken-Schröder, \& Iacobucci, 2001). Theory in business relationship marketing similarly includes the proposition that some pairs of buyers and sellers have strong personal relationships and these pairs are more committed to maintaining the relationship than less socially bonded partners (Wilson, 1995). Survey research studies by Wilson and Mummalaneni (1986) and Mummalaneni and Wilson (1991) support this proposition, although Han and Wilson (1993) find that social bonding did not contribute to buyer-seller commitment in a relatively complex buying context. Rodríguez and Wilson (2002) propose that perceived strength of social bonds affects trust in the business partner positively and that both social bonds and trust influence commitment to the relationship, where two of their measures of commitment ask about their level of inputs into a relationship, which infers greater input of resources of the type this study investigates. Rodríguez and Wilson support these two propositions in analyses of survey data on U.S. and Mexican interfirm strategic alliances.

Relevant theory includes the perspective that psychological antecedents include "personal bonding" or "social bonding" (Han, 1991; Wilson \& Mummalaneni, 1986) and 
social bonds "encompass resources that are emotional or affective in nature. As such, social bonding entails familiarity, friendship, and personal confidence built through interpersonal exchange. Social bonding measures the strength of a personal relationship and may range from business to close, personal ties" (Rodríguez \& Wilson, 2002, p. 55). Thus, the concept of social bonding as a resource antecedent in business marketing-customer relationships provides theoretical ground for the proposal that social bonding as a resource associates with the investment of other resources in the relationships. While not referring to social bonding specifically, Anderson (1995) and Anderson and Narus (1991, p. 346, italics in the original) express the view that the prosperity of firms depends on having "close, collaborative, relationships with selected suppliers, customers, and value-added retailers. Thus, management thinking has advanced to gaining a better understanding of which firms they ought to engage in these collaborative relationships and how to make these relationships work in practice."

While research on the impact of social bonding on trust and commitment supports the occurrence of interfirm social relationships, the propositions relating to the association of social bonding with the allocation of other resources and social bonding's unique influence on the prosperity of the firm are topics for empirical investigation. The empirical literature deals with these issues only to a limited extent. For example, "Industrial Marketing and Purchasing" (IMP) researchers investigate the link between "relationship atmosphere" and resource ties in business-to-business relationships in case analyses (Håkansson, 1982), but not in more generalizable quantitative studies. Researchers do not appear to have studied independence of the effects of financial and social bonds on relationship outcomes in depth.

This study's $\mathrm{H}_{1}$ and $\mathrm{H}_{2}$ derive from the discussion relating to the study's first research question concerning strength of social bonds and their relationship to supplier allocation of resources. H1: Social bonding in interfirm relationships has a positive influence on suppliers' 
allocation of resources to customers. H2: The positive social-bonding influence in interfirm relationships on suppliers' relative allocation of resources has an effect that is independent of the impact of financial bonds between customers and suppliers. These hypotheses are precursors to $\mathrm{H}_{3}$ to $\mathrm{H}_{5}$, which relate to the second research question about the effect of time on the relationship between bonds and resource allocation. Both social and financial bonds in the study are at the level of the relationship, rather than at the individual level, as the data collection section explains.

$\mathrm{H}_{1}$ derives from the literature-based indication that social bonding is a resource antecedent to relationship outcomes. In S-DL terms (Vargo \& Lusch, 2004), social bonds are very much towards the operant ("acting on") end of the spectrum of resource types, whereas the resources whose allocation the study assesses as an outcome are more towards the operand ("acted on") end of the spectrum. The relationship actors, through their social bonds, act on these resources and thereby affect their supply and their exchange. In a longitudinal study comparing relationship marketing theories, Palmatier, Dant, \& Grewal (2007) find that the RBV provides a unifying view of relationship constructs. On the basis of the RBV, they note that relational norms and consequent relationship bonds lead to sellers' relationship specific investments (as well as buyers' relationship specific investments). Specific to the business relationship context of this study, Wilson (1995, Figure 2, p. 340), based on Dwyer, Schurr, and Oh (1987) and Ford (1990), states that social bonds antecede nonretrievable investments. Specific to this study, the actors' social bonds will affect the extent to which the supplier will allocate financial, physical, time, and intangible resources to the relationship.

Ford (1980, p. 349) notes that one of the developments over time in a successful relationship is that social distance decreases and also notes that the management of relationships must link to the company's "allocation of its resources between different relationships according to the likely return." A range of relationship marketing literature 
infers that social bonds positively affect the allocation of resources by a seller to a relationship with a buyer, but prior studies do not test this relationship. $\mathrm{H}_{1}$ is therefore worthy of testing.

Supporting H2, the limited research into the independence of financial and social bond effects on relationship outcomes in the business-to-business context indicates that though they may be related, they do have distinct effects in the business-to-consumer context, for example in Ahmad and Buttle's (2001) research. Similarly, Berry and Parasuraman (1991) describe a hierarchy of increasing effectiveness from financial bonding alone through to the highest level where financial, social, and structural bonding are employed. Turnbull and Wilson (1989), in an industrial context, discuss the greater strength of structural bonds than social bonds, and allude to the lower effectiveness of financial bonds. However, apart from assessment of discriminant validity of the bond types from the buyer's perspective in consumer contexts (Chiu, Hsieh, Li, \& Lee, 2005) and their distinct effects on business-tobusiness relationship outcomes (Palmatier et al., 2006), there is not a great deal of testing of their independence and especially not the distinct effects of these bond types specific to resource allocation. The literature thus indicates $\mathrm{H}_{2}$ is important for testing both its own right and because the later hypotheses of this study depend on the independence of the effect of social bonds for their rigor. In defining financial bonding, this study takes its lead from the buyer perspective of Berry (1995), Ahmad (Ahmad, 2005), and Chiu et al. (2005) that financial bonding, in part, is a matter of pricing. The study thus defines financial bonding from the seller perspective as a matter of profitability.

2.2 Alternative models of social bonding's time influence on supplier allocations of other resources

The second research question builds on the first and concerns the interaction of social bonds, length of relationship, and supplier resource allocation. This article conceptualizes 
length of relationship (time) as having an interaction effect, meaning that length of relationship affects the extent to which higher social bond strength is associated with higher resource allocation by the seller to the relationship with the buyer. Length of relationship works together with higher social bond strength. Because Armstrong, Brodie, and Parsons (2001) and Carlsmith et al. (1976) advocate the investigation of competing models to advance science, Figure 1 presents for investigation three potential alternative models of social bonding's time-based relationships with supplier resource allocation. These alternative explanations are not the only possible explanations, but they do exist in the relevant literature, as the following exposition develops.

Figure 1 here.

The Imprinting Model. The first potential time-based explanation, "imprinting model", or consistent growth model, predicts no interaction effect for social bonding and length of the relationship on supplier allocation of resources (Panel C in Figure 1). The old saw, "You don't get a second chance to make a first impression," reflects thinking that supports consistent growth theory. Consistent growth theory recognizes that no relationship starts out as a strong tie, but interfirm embeddedness works as a priming mechanism through which small initial offers of trust and assistance strengthen into a resilient tie, provided that they are reciprocated (Heugens \& Zyglidopoulos, 2008). Pursey et al. (2008, p. 332) stress that the interfirm "relationship acquires a social character above and beyond the technical characteristics of the exchange at hand (Granovetter, 1985). As the exchange loses its anonymity, partners start building relationships in which trust and mutual reliance rise to the fore (Uzzi, 1999).” 
The proposition is that interfirm imprinting provides an advantage for a customer (or supplier) in an interfirm relationship that consistently carries across many exchange occasions and many years of the relationship, rather than increasing or decreasing with time. This micro view of interfirm relationships is viewable as an extension of Stinchcombe's (1965) proposal concerning macro-economic and technical conditions, as the imprinting forces, affecting appropriate organizational form in terms of social structure. Subsequent research suggests that imprinting may have long lasting effects upon the strategies, strategic choices, and operating practices of the firm (Kriauciunas \& Shinkle, 2008, p. 4). "We consider Organizational Imprinting the forgotten theory, since the impact of imprinting has been understudied, under recognized, or both. We believe this has occurred due to two reasons: (1) research that reflects organizational imprinting has been misclassified as something other than imprinting, and (2) research related to firms has not fully addressed the initial point of firm behavior which is a topic that can be enhanced by imprinting theory" (Kriauciunas \& Shinkle, 2008, p. 10). $\quad \mathrm{H}_{3}$ expresses the imprinting model. $\mathrm{H}_{3}$ : no interaction effect occurs for social bonding and length of the relationship with a business-to-business customer on the supplier's allocation of resources to the customer relative to other customers.

The Honeymoon Model. The "honeymoon model" (Panel A in Figure 1) is a descriptive term that suggests an alternative to imprinting: that a negative interaction effect occurs for social bonding and length of the relationship on resource allocation (cf. Deeds \& Rothaermel, 2003; Fichman \& Levinthal, 1991). According to the honeymoon model, the highest level of social bonding occurs early in supplier-customer relationships and this bonding results generally in high level of supplier resource allocations to customers having such early high levels of social bonding. However, the effect of a high social bonding level decreases over time. The differences among supplier resource allocations to different buyers decrease as familiarity increases, so that the buyers who got high resource allocations initially 
get lower allocations later in the relationship lifetime, whereas those buyers who got lower allocations get higher allocations later and come closer as shown by convergence in the Panel A lines over time.

Becoming accustomed in the relationship takes some of both the joy and the pain out of the interactions. Rationale: all relationships eventually include problems and misunderstandings that result in declines in social bonding levels between suppliers and customers so that even though a supplier may allocate greater resources to customers with high versus low social bond levels in late, well-established, relationships, the differences in resources allocation is substantially less in comparison to the respective allocations made in early-stage relationships.

Fichman and Levinthal (1991) inform the theoretical model for the occurrence of honeymoon relationships:

In contrast to the emphasis in the literature on the liabilities of newness... relationships can start with some initial stock of assets, which (depending on the particular context) can include favorable prior beliefs, trust, goodwill, financial resources, or psychological commitment. ... if a relationship starts with an initial stock of assets, the risk of the relationship dissolving at its inception is reduced, even if the initial outcomes of the relationship are unfavorable. These unfavorable outcomes can take the form of poor performance evaluations in the context of employment relations or unsatisfactory service in an inter-organizational relationship. ... the duration of this honeymoon period is likely to vary with the magnitude of these initial assets. (Fichman \& Levinthal, 1991, pp. 443- 
However, Fichman and Levinthal's (1991) review of the empirical literature supporting the existence of such relationships does not examine the roles of specific assets (e.g., social bonding and financial bonding) supporting or refuting their main proposition that relationships are unlikely to terminate early in a relationship. Further, the Fichman and Levinthal (1991) review does not examine how the stock of assets in a relationship affects dollar, physical, time, and intangible resource allocations into the relationships. Considering the shape of association of length-of-time in relationships and the dissolution of the relationships as Fichman and Levinthal (1991) report does not indicate how asset stocks are influencing resource allocations for new, adolescent, and mature relationships. Support or refutation of the honeymoon model and alternative models of relationship stock assets on relationship behaviors requires specifically empirically examining assets and behavior outcomes within the relationship-behavior outcomes such as resource allocations by one or both parties in the relationship.The current study does this by testing the honeymoon hypothesises. $\mathrm{H}_{4}$ : Social bonding and length of the relationship with a business-to-business customer has a negative interaction effect on the supplier's allocation of resources to the customer relative to other customers.

The Maturity Model. In comparison to the honeymoon model, the "maturity" model suggests the opposite. The impact of strong versus weak social bonds grows stronger over the years (Panel B in Figure 1). Over time some business-to-business relationships build up high versus low levels of interdependency, trust, and comfort in comparison to others. High levels of these assets serve to increase the relative allocations of resources by firms in the relationship. 
Baum and Ingram (2002, p. 193) suggest that interdependencies and relational embeds in "interfirm" organizational groups build from resource procurements and allocations, uncertainty reduction, and the creation of stable, preferential, relationships.

We argue that interfirms are structured around a broad set of economic and non-economic interdependencies, facilitating organizational cooperation in pursuit of many different interests... In broad terms, interdependence focuses on two considerations: resource procurement and uncertainty reduction (Pfeffer \& Salancik, 1978). Organizations form inter-organizational relations to access resources that are essential to pursuing their goals but are at least in part controlled by other organizations. (Baum and Ingram 2002, p. 193)

Baum and Ingram (2002) and Baum, Shipilov, and Rowley (2003) stress the role of relational embeddedness in deepening and strengthening interfirm relationships. Relational embeddedness highlights effects of dyadic ties between firms on subsequent cooperation between them (Gulati \& Gargiulo, 1999). To reduce search costs and alleviate risks of opportunism that might occur with interfirm relationships, firms tend to create stable, preferential relationships characterized by trust and rich information exchange with specific partners. Prior direct ties provide channels through which each partner can learn about the competencies and reliability of the other, amplifying trust and diminishing uncertainty associating with future ties (Chung, Singh, \& Lee, 2000; Gulati, 1995). Baum et al. (2003) offer an empirical study showing that the working ties among banks expand with the maturing of relationships. Although their empirical research on maturity theory in interfirm relationships does not address directly the following issue, it does suggest the following hypothesis to test the maturity model. $\mathrm{H}_{5}$ : social bonding and length of the relationship with 
a business-to-business customer has a positive interaction effect on the supplier's allocation of resources to the customer relative to other customers.

\section{METHOD}

The method for empirically testing the hypotheses included several steps: exploratory interviews with managers, measurement development and pretesting, pretesting the instrument, survey data collection, and data analysis. The study conducted and analyzed seven exploratory interviews with managers to check face validity of the constructs. The following sections give more detail of this process.

\subsection{Measurement Instrument Development and Testing}

A mail survey collected data to test the hypotheses. Prior to the main survey, the study included the development of the single-item scales (Rossiter, 2002) for the focal concepts in the hypotheses. Rossiter's (2002) procedure for scales relies on construct definition and content validity as the primary drivers of the item or items in the scale, rather than statistical procedures such as structural equation modeling. The procedure identifies the object of the measurement, attributes of the construct, and the entity that rates the construct. Using Rossiter's concepts, the object of the questionnaire is a single clearly identified buyerseller relationship for each respondent, which fits the definition of a "concrete" object. The questionnaire used seven-point Likert-type statements, with only the end points of the scales labeled. The anchor points for supplier allocation of resources relative to other relationships were "Very much lower" to "Very much higher". For relationship bonding items, the anchor points were "I do not agree at all" to "I fully agree". To assess relationship duration, the survey asked sample frame members to write in the number of years their firm had a relationship with the focal customer.

Academics with knowledge of the relationship field and others with expertise in questionnaire design worked through the draft questionnaire and made comments. After 
appropriate modification to the questionnaire, five practitioners then worked through it. These processes resulted in minor additional modifications. The researchers then mailed out 200 pilot questionnaires. The 28 responses from this pilot survey indicated that there was a need to specify more exactly the selection criteria by the respondent for choice of subject for the questionnaire.

The pilot study established that if respondents chose for themselves which relationship they used as the subject for questionnaire answers, many chose a customer that they perceived favorably on all items, thereby providing skewed data with less variance than desired for effective analysis. Hence, based on an approach used by Anderson and Narus (1990), respondents to the main survey selected their fourth largest customer as the subject. This approach, reinforced by discussion of their fourth largest customer with several sales managers prior to mailing the main survey, obtained a spread of relationship types. The received surveys include a wide range of relationship durations and standard deviations ranging from 1.1 to 1.6 on the 1-7 scale for the items used in the study.

The questionnaire asked respondents to choose one specific relationship as subject, so the unit of analysis is a relationship, not the individual. The introduction to the questions in section $\mathrm{B}$ of the appendix, which includes the questions for social and financial goals and a validation question, was as follows, thus emphasizing the relationship as unit of analysis: "How much do you agree with the following statements about your firm's relationship with the chosen customer, as compared with other customers?" The study's validation item, "Our firm shares a lot of goals with this customer", examines the nomological validity of the constructs. Wilson (1995) proposes that establishing strong mutual goals has the widest range of associations in integrating relationship variables and in the relationship development processes. Meeting theoretical expectations, the responses to "sharing a lot of goals" more closely relate to the social and financial bonding items than to the resource allocation items or 
length of time in the relationship. The findings confirm these predictions; Table 2 in the results section reports the correlations of all items with the validation item.

The appendix includes the specific instructions and scale items in the survey for the four supplier resource allocations in the study: dollars, physical items, time, and intangible inputs. The appendix also includes the specific instructions and items for social and financial bonding relationships.

\subsection{Sample and Data Collection}

The procedure included distributing the self-administered mail questionnaire to a randomly selected sample from a sample frame comprising managers in marketing or sales positions in New Zealand suppliers or distributors of manufactured goods on the database of a multinational directory company. After telephone verification of recipient names and addresses, the mail-out of 1407 questionnaires achieved 318 responses after mailing of a postcard reminder, for a $23 \%$ response rate. Of the 318 responses, 314 were usable. Analysis of early and late responses, as Armstrong \& Overton (1977) suggest for assessing nonresponse bias, indicated no significant differences in $t$-tests of key items in the questionnaire.

The New Zealand economy is a small one, thus, the sample is a good representation of the size of companies in the sector and the distribution of sizes is similar to that in the sample frame. The respondents were mainly sales managers (45\%), marketing managers (21\%), sales and marketing managers (14\%), or in a CEO/General Manager /Director position (9\%). Others were in positions such as product manager or customer service manager, making them qualified to respond concerning relationships with buyers. The buyers that respondents used as questionnaire subjects came from a range of primary product, manufacturing, and service firms. 


\subsection{Data Analyses}

Bivariate correlations assess relationships between social and financial bonds on one hand and four resource-allocation constructs on the other hand. Partial correlation analysis assesses the effect of social bonds independent of financial bonds. Path models (estimating the standardized regression weights (betas) using multiple regression analysis for main and interaction effects on the dependent variable (see Pedhazer, 1997), are used to illustrate the relationships between social bonding, financial bonding, years in relationship and their resource allocation outcomes. The examinations of relationships include tipping point analysis, as McClelland (1998) recommends and illustrates for psychological variables. McClelland (1998) observes that the changes in a psychological or societal variable make little difference until they reach a certain level. Relationships for the independent variable and outcome variables are often nonlinear and not well described by correlation coefficients. Instead, they are described accurately as tipping points (Gladwell, 1996). In his 1998 paper, McClelland divides scores for an independent construct to form five groups of respondents from very low to very high and reports each group's scores for a dependent construct and recommends comparing the groups with very low and the very high scores to reduce noise inherent in data and to achieve high clarity in interpreting relationships. The present study also includes this data analysis method.

The analyses include examining relationships using the full range of scores and also using summary measures of low (1-3), medium (4-5), and high (6-7) social and financial bonding scores. The findings using these alternative scoring procedures differed very little to not at all. Consequently, the findings in this article are for the summary measures of low, medium, and high social bonding scores (low $=1$, medium $=2$, and high $=3$ ). 


\section{FINDINGS}

\subsection{Social Bonding and Supplier Resource Allocations}

The findings of data analyses in Table 1 and Figure 2 support $\mathrm{H}_{1}$ : Social bonding in interfirm relationships has a positive influence on suppliers' allocation of resources to customers. The findings show a consistent pattern for allocations across the four categories of resources: dollars, physical items, time, and intangibles.

Table 1 and Figure 2 here.

The ANOVA findings are significant statistically $(\mathrm{p}<.000$ for 3 of the 4 categories of resources) and the $\eta^{2}$ (eta squared) values indicate modest but meaningful effects sizes for three resource categories. The patterns of resource allocation scores indicate an overall linear increasing impact of social bonding on supplier resource allocations: lowest allocations for the informants in the total low social bonding group in Figure 2 and highest allocations for the informants in the total high social bonding group.

\subsection{Nomological validity: shared goals}

The study uses a question about shared goals (appendix section B) to test nomological validity. Shared relationship goals have a strong association with other relationship constructs (Wilson, 1995) and should therefore correlate significantly with these constructs. The correlations of shared goals with other items are in the last column of Tables 2 and 3. All are significant except with relationship length, thus supporting nomological validity.

\subsection{Social Bonding's Influence on Resource Allocation Controlling for Financial Bonding}

The findings support $\mathrm{H}_{2}$ : The positive social-bonding influence in interfirm relationships on suppliers' relative allocation of resources has an effect that is independent of 
the impact of financial bonds between customers and suppliers. Table 2 includes the bivariate and partial correlations of social bonding and financial bonding influences with the four supplier resource allocations.

Table 2 here.

Table 3 shows these correlations after correction for common method variance. Our analysis estimates a regression model, with a cubic term and coefficients that best fit Podsakoff, Mackenzie, and Podsakoff's (2003) meta-analysis data for true and observed correlation, and applies it to our data to obtain the corrected data in Table 3. Podsakoff et al. (2003) base their analysis on Cote and Buckley's (1987) estimates. The regression model's correction accounts for the fact that, as the Podsakoff et al. data shows, low correlations tend to be inflated and higher correlations tend to be deflated by common method variance. The regression model is a cubic function with adjusted $\mathrm{R}^{2}=.989$ :

$$
\text { Actual }=-0.19+(1.034 * \text { Observed })+\left(4.394 * \text { Observed }^{2}\right)-\left(4.392 * \text { Observed }^{3}\right)
$$

where "Observed" is the correlation observed in analysis as in Table 2 and "Actual" is the estimate of the actual correlation, compensating for inflation of low correlations and deflation of high correlations by common method variance; values above 1 are set to 1.00 and values below 0.00 are set to 0 .

Table 3 here.

The bivariate correlations indicate statistically significant relationships for social bonding (and financial bonding) with all four resource allocation constructs. Three of the four partial correlations of social bonding with the four resource allocation constructs, 
controlling for financial bonding, are significant statistically both before and after correcting for common method variance (CMV). The partial correlations with and without the adjustment for CMV indicates that the sharing of physical equipment is the only supplier resource that does not associate significantly with social bonding. Figure 2 is a visual of the mean scores for resource allocations in dollars for the three levels of social bonding controlling for the three levels of financial bonding. Focusing on the low versus high levels of social bonding by the low level versus the high level of financial bonding indicates modest increases in dollar resource allocations: 3.77 to 3.94 and 4.67 to 4.83 , respectively. A consistent pattern is observable in Figure 2 for low-to-high social bonding for the medium level of financial bonding as well: 4.25 to 4.47 . Such patterns of modest increase in resource allocations occur for 11 of the 12 possible comparisons for the other three resource allocations (physical items, time, and intangibles) for the low to high social bonding range, controlling for the three levels of financial bonding ( $\mathrm{p}<.01$ by a sign test).

\subsection{Social Bonding's Influence on Resource Allocation Controlling for Shared Goals}

Shared relationship goals have a strong association with other relationship constructs (Wilson, 1995) and are therefore likely to affect the relationships between these constructs. The study therefore uses shared goals as another control variable for the relationship between social bonding and resource allocations, because it could be a problem if supplier managers allocate resources to buyers that do not have shared goals with the supplier.

Partial correlations show that the positive social-bonding influence in interfirm relationships on suppliers' relative allocation of resources is also independent of the impact of shared goals between customers and suppliers. Partial correlations are all significant except for that between social bonds and physical equipment, ranging from .2 to .13 , with significance from $\mathrm{p}<.05$ to $\mathrm{p}<.001$. 


\subsection{Findings Relevant for the Imprinting Model}

Figure 3 shows the data from the dollars column of Table 1. The points on Figure 3 are the points for relationship length 1 to 5 years through to $17+$ years, for each of the low, medium and high social bonding groups. Examining Figure 3 makes clear that the findings do support $\mathrm{H}_{3}$, that is, the imprinting model that appears in Panel $\mathrm{C}$ of Figure 1. No interaction effect occurs for social bonding and length of the relationship with a business-tobusiness customer on the supplier's relative allocation of resources to the customer. The findings in Figure 3 indicate long-lasting relative supplier resource commitment suffers for operating conditions of low social bonding but flourishes for operating conditions that include high social bonding.

Examining the findings in Table 1 and Figure 2, the imprinting model receives support for two of the four resource allocations: dollar and physical items. A path model for dollar resource allocation supports the imprinting model. The findings of this path model and the path models for the other three resource allocations appear in Figure 4. The advantage in receiving relatively greater resource allocations from suppliers for customers having high versus low social bonding relationships is greater for mature than it is for new relationships. Time does not heal or nurture wounds that may exist in low social bond relationships.

Figure 3 here.

\subsection{Findings Relevant for the Honeymoon Model}

The findings do not support the honeymoon model as Table 1 shows. Table 1 reports means, standard errors, and sample sizes for the relevant comparisons. Unlike the prediction of the honeymoon model, the resource allocation means for the informants reporting high 
social bonding with their fourth largest customers consistently are higher (not lower) for mature versus new relationships for all four resource allocation categories.

Figure 4 here.

Illustrative of similar patterns observable for allocations of all four resources (Table 1), Figure 3 plots the means in Table 1 for dollar resource allocations for the five time periods controlling for the three levels of social bonding. Considering a tipping-point analysis (McClelland,1998) of the extreme new-to-mature relationships for the low-to-high social bonding means, the findings for the three dotted-lines most resemble the imprinting model rather than the other two proposed models for the dollar resource allocations, because they have similar gradients. They therefore show no great difference in resource allocation across differing relationship durations. Thus, the findings do not support $\mathrm{H}_{4}$; no statistically significant negative beta coefficient occurs for the interaction term of social bonding and length of relationship on the supplier's relative allocation of resources to the customer

\subsection{Findings Relevant for the Maturity Model}

The findings offer mixed support for the maturity model for two of the four-resource allocation categories. Modest decreases in average resource allocation occur in the low social bonding group for "time that your personnel spend working on the relationship" and “intangible inputs, such as knowledge, skills, ingenuity, and your business contacts" across the relationships in the five time periods. In contrast, increases occur for these two resource allocation categories across the relationships in the five time periods for the high social bonding groups. See Table 1 for these findings.

The tipping-point observed patterns for the time and intangible resource allocations match with the maturity model. Customers in long-term sour relationships with suppliers are 
particularly likely to receive less time with supplier personnel and receive less intangible inputs of knowledge, skills, ingenuity, and business contacts (KSIB) in comparison to customers in long-term sweet relationships. However, these observations only follow from examining the findings in Table 1. Path analyses of social bonding, years in the relationship, and their interactions to explain each of the four resource allocations do not support a social bonding-by-years in the relationship interaction effect. Specifically, the findings do not support $\mathrm{H}_{5}$; no statistically significant positive beta coefficient occurs for the interaction term of social bonding and length of relationship on the supplier's relative allocation of resources to the customer.

For the path models in Figure 4, the presence of the interaction term for social bonding and financial bonding without the independent term for either bonding variable for three of the four resources, specifically physical items, time, and intangibles, supports Wilson's (1995, p. 339) proposition that the interaction of relationship bonds "may be greater than the sum of their parts in creating a force to hold a relationship together" (and, as the present study indicates, to encourage the allocation of resources). The interaction terms alone in three of the four path models in Figure 4 indicate that the combination of high social bonding and high financial bonding usually results in higher levels of resource allocations than high-medium or high-low combinations of these two bonding processes. Examination of averages for the nine combinations of three social bonding levels by three financial bonding levels supports this conclusion for allocations across all four resources.

\section{DISCUSSION: IMPLICATIONS FOR THEORY AND PRACTICE}

The findings of the present study support propositions that are important for both researchers and managers. First, high versus low social bonding positively affects the supplier allocations of tangible and intangible resources to customers. Prior research clearly shows that sellers need to maintain strong social bonds and invest in social programs with 
their customers, as noted above; this study shows that such investment is also important for managers in dealing with their suppliers. Second, the positive social bonding influence on resource allocations occurs independently to some meaningful extent from the impact of financial bonding on resource allocations: this is a clear indication to managers that social bonds with their suppliers are important in their own right and that financial bonds and good profits are not the only way to encourage a supplier to invest in a relationship with them.

Third, the study demonstrates that social bonding's influence on resource allocation occurs in mature as well as new relationships, so managers likely will benefit by starting well with a supplier and to continue to invest in the relationship. Fourth, the maturity and imprinting models of social bonding's influence on supplier resource allocations are more germane than the honeymoon model — the particular model most relevant appears to be contingent on the particular resource under examination. This finding has implications for strategies: in planning bonding strategies, managers need to think in terms of which resources they most wish to gain from their suppliers and invest accordingly. Fifth, the highest levels of supplier resource allocations occur in conditions of high social bonding in conjunction with high financial bonding for three of the four resource allocations: allocation of physical items as resources is the exception. The comparison of this best conjunction with the opposite conjunction is a striking message for managers, as the means of 4.83 versus 3.77 shows in Figure 2 for "dollars your firm puts into the relationship."

These conclusions support both Homans' (1958) theoretical (and still radical) perspective in sociology and Wilson and Jantrania's (1994) rationale for practice in adopting a relationship versus a transactional mode of interfirm behavior. Homans (1958, p. 597) theoretically proposes that viewing "social behavior as an exchange of goods may clarify the relationships among four bodies of theory: behavioral psychology, economics, propositions about the dynamics of influence, and propositions about the structure of small groups." 
High social bonding serves as a foundation or lubricant for customers for gaining financial, physical, time, and important intangible (KSIB) allocations from suppliers. Homans (1958, p. 606) implies such a view is anathema in sociology, "Of all our many 'approaches' to social behavior, the one that sees it as an economy is the most neglected, and yet is the one we use every moment of our lives--except when we write sociology." Wilson (1995) observes that one of the largest barriers to adoption of the relationship model is the organizational reward system, which encourages buyers to drive for lower prices and salespeople to sell, not manage a relationship, thus maintaining an adversarial environment. Senior management often talk relationships while the managers charged with implementation operate in a transactional mode, which makes trust development and the achievement of mutual goals difficult if not impossible. Implementation of relationships requires changes in corporate culture and reward systems to reinforce the behaviors that generate trust, mutual goals and adaptation, and the other critical variables in the creation of a strong hybrid relationship. (Wilson, 1995, p. 344)

This study provides cogent reasons for managers in buyer firms to develop strong social bonds because social bonds, independently of financial bonds, help determine the resources that their suppliers will allocate to their relationships, which will influence relationship outcomes. Theory development and advancing metrics that provide evidence supporting the tenets of the relationship model (such as the unique contribution of social bonding in influencing supplier allocation of tangible and intangible resources) are likely necessary precursors to the paradigm shifts in corporate culture and reward systems that Wilson (1995) advocates. The study's outcomes are also interesting for senior managers in sellers, particularly the independence, from financial bonds and shared goals, of the 
relationship between social bonds and resource allocation: allocation of resources to buyers that are neither profitable nor have shared goals could be problematic.

\section{LIMITATIONS}

The empirical study that this report describes involves cross-section, survey, selfreport data using fixed-point responses from one manager per firm and one side of a suppliercustomer relationship. While this profile of business-to-business research study may dominate the business-to-business research, each characteristic of the method possesses important limitations. Certainly the need for longitudinal research methods is relevant for the study of social bonding processes and their influence on suppliers' resource allocations to customers, and vice versa. Longitudinal methods are challenging to apply and generate the issue of generalizability because of the small number of interfirm relationships that such studies typically examine; however, the increase in nuance, relationship coverage, and accuracy that longitudinal studies provide justify the substantial effort in doing such studies.

Self-report surveys using fixed-point responses from one informant per firm invite discussion of several issues. Do other persons in the supplier firm have highly similar beliefs toward the same customer as the informant's beliefs? Certainly some variability in the responses would occur; and some of multi-person responses are likely to vary substantially for some share of suppliers if such research would include interviews with two or preferably more informants per firm. Similarly, substantial variability in customer responses versus the supplier's responses would occur for some share of customers--how does substantial variance in responses versus consistently the same responses between suppliers and customers influence the associations of the social bonding and resource allocations constructs? Further, relating to social bonding theory and metrics, the second party (person) in an interfirm relationship may not perceive or report the same degree of social bonding as the first party in this relationship. 
Also, the use of only seven-point self-reports for relative resource allocations limits the value of the study. Do the respondents' beliefs about the level of relative resource allocations match independent assessments of these allocations? For example, do the reports about "the amount of time that your personnel spend working on the relationship" with this customer match with independent records of telephone calls, faxes, emails, and face-to-face visits with this customer and in-firm discussions about this customer? Relevant literature does include the use of different data sources to confirm self-reports versus observed behaviors in research on marketing-consumer relationships (Aurier \& N'Goala, 2010); such research would be useful to emulate in business-to-business research contexts. In conjunction with this question is the value of seven-point scales requiring informants to transform knowledge about concepts, interactions, and beliefs about one customer into a number ranging from 1 to 7 . Even though informants are able to do so, the collection of emic "thick-descriptions" (Geertz, 1973) of events and processes leading to the fixed-point responses would improve the value of such studies.

The findings relate to manufacturers and distributors of manufactured products in one developed country. Replications of the research and findings on an industry-by-industry level and for several nations might confirm the validity of the findings that this article describes. Thus, while the findings in the present study appear to be informative, the limitations suggest the need for caution in considering the accuracy and generalizability of the findings. The findings in this report are suggestive and may be appealing but confirmation of the findings using other methods in additional industries, and in other nations, is necessary.

Because the data permit only cross-sectional and not longitudinal analyses, these findings do not fully test the honeymoon model or the two other hypothesized social bonding models by time. Conceptualizing honeymoon versus post-honeymoon relationships implies 
that longitudinal analysis is more relevant than cross-sectional relationships. Relationships are more likely to terminate earlier when either party believes that low versus high social bonding describes the relationship. Examining the sustainability and termination of suppliercustomer relationships at the interfirm level would be a challenging undertaking that this study leaves for future research.

\section{CONCLUSIONS AND SUGGESTIONS FOR FUTURE RESEARCH}

The present study theoretically extends the possibility that social behavior in its elementary form of social bonding affects supplier allocations of scarce resources--dollars, time, physical items, and intangibles (KSIB). Findings from a preliminary survey of suppliers in manufacturing and distribution firms in one economically developed country confirm this theoretical extension. Additional research within industries and across several nations that incorporates examining the social bonding beliefs for both suppliers and customers within specific interfirm relationships is worthy of consideration.

Wilson's (1995, p. 342) observation still appears accurate for now and beyond, “Our knowledge about relationships is at an early stage." While the interaction model (Håkansson, 1982; Walter, Hölzle, \& Ritter, 2002) of the IMP Group serves well in advancing relationship marketing theory, and in demonstrating research methods that include in-depth interviews of multiple informants among supplier and customer firms, research focusing on advancing theory and testing micro (elementary) social behavior within-the-same interfirm relationships still is at an early stage of development. This study's findings, which focus on social behavior at the relationship level, help advance this knowledge development. 


\section{REFERENCES}

Ahmad, R. (2005). A conceptualisation of a customer-bank bond in the context of the twentyfirst century UK retail banking industry. The International Journal of Bank Marketing, 23(4/5), 317.

Ahmad, R., \& Buttle, F. (2001). Retaining business customers through adaptation and bonding: A case study of HDoX. The Journal of Business \& Industrial Marketing, 16(6/7), 553.

Anderson, J. C. (1995). Relationships in business markets: Exchange episodes, value creation, and their empirical assessment. Journal of the Academy of Marketing Science, 23(4), 346-350.

Anderson, J. C., \& Narus, J. A. (1990). A model of distributor firm and manufacturer firm working partnerships. Journal of Marketing, 54(January), 42-58.

Anderson, J. C., \& Narus, J. A. (1991). Partnering as a focused market strategy. California Management Review, 33(3), 95-113.

Armstrong, J. S., \& Overton, T. S. (1977). Estimating nonresponse bias in mail surveys. Journal of Marketing Research, 14 (August), 396-402.

Armstrong, J. S., Brodie, R. J., \& Parsons, A. G. (2001). Hypotheses in Marketing Science: Literature Review and Publication Audit. Marketing Letters, 12(2), 171-187.

Arrow, K. J. (1974). The limits of organization. New York: Norton.

Aurier, P., \& N'Goala, G. (2010). The differing and mediating roles of trust and relationship commitment in service relationship maintenance and development. Journal of the Academy of Marketing Science, 38(3), 303-325. doi:10.1007/s11747-009-0163-z

Bagozzi, R. P. (1995). Reflections on Relationship Marketing in Consumer Markets. Journal of the Academy of Marketing Science, 23(4), 272-277. 
Bamford, C. E., Dean, T. J., \& McDougall, P. P. (2000). An examination of the impact of initial founding conditions and decisions upon the performance of new bank start-ups. Journal of Business Venturing, 15(3), 253-277.

Barney, J. B. (1986). Strategic factor markets: Expectations, luck and business strategy. Management Science, 32, 1231-1241.

Barney, J. B. (1991). Firm resources and sustained competitive advantage. Journal of Management, 17(1), 99-120.

Bator, F. M. (1958). The anatomy of market failure. Quarterly Journal of Economics, 72(3), 351-379.

Baum, J. A. C., \& Ingram, P. (2002). Interorganizational learning and network organization: Toward a behavioral theory of the interfirm In M. Augier \& J. G. March (Eds.), The economics of choice, change and organization: Essays in memory of Richard M. Cyert. Cheltenham, U.K.: Edward Elgar.

Baum, J. A. C., Shipilov, A. V., \& Rowley, T. J. (2003). Where do small worlds come from? Industrial \& Corporate Change, 12(4), 697-725.

Baxter, R., \& Matear, S. (2004). Measuring intangible value in business to business buyerseller relationships: An intellectual capital perspective. Industrial Marketing Management, 33(6), 491-500.

Baxter, R. (2012). How can business buyers attract sellers' resources?: Empirical evidence for preferred customer treatment from suppliers. Industrial Marketing Management, 41(8), 1249-1258. doi:http://dx.doi.org/10.1016/j.indmarman.2012.10.009

Berry, L. L. (1995). Relationship Marketing of Services--Growing Interest, Emerging Perspectives. Journal of the Academy of Marketing Science, 23(4), 236-245.

Berry, L. L., \& Parasuraman, A. (1991). Marketing Services: competing through quality. New York: Free Press. 
Blau, P. M. (1964). Exchange and Power in Social Life. New York: Wiley.

Boeker, W. (1989). Strategic change: The effects of founding and history. Academy of Management Journal, 32(3), 489-515.

Cantù, C., Corsaro, D., \& Snehota, I. (2012). Roles of actors in combining resources into complex solutions. Journal of Business Research, 65(2), 139-150. doi:10.1016/j.jbusres.2011.05.013

Carlsmith, J. M., Ellsworth, P. C., \& Aronson, E. (1976). Methods of research in social psychology. Reading, MA: Addison-Wesley.

Chiu, H.-C., Hsieh, Y.-C., Li, Y.-C., \& Lee, M. (2005). Relationship marketing and consumer switching behavior. Journal of Business Research, 58(12), 1681-1689.

Chung, S., Singh, H., \& Lee, K. (2000). Complementarity, status similarity and social capital as drivers of alliance formation. Strategic Management Journal, 21(1), 1.

Cote, J. A., \& Buckley, M. R. (1987). Estimating Trait, Method, and Error Variance: Generalizing Across 70 Construct Validation Studies. Journal of Marketing Research, 24(3), 315-318.

Day, G. S., \& Wensley, R. (1988). Assessing advantage: A framework for diagnosing competitive superiority. Journal of Marketing, 52(2), 1-20.

De Wulf, K., Odekerken-Schröder, G., \& Iacobucci, D. (2001). Investments in Consumer Relationships: A Cross-Country and Cross-Industry Exploration. Journal of Marketing, 65(4), 33-50.

Deeds, D. L., \& Rothaermel, F. T. (2003). Honeymoons and liabilities: The relationship between age and performance in research and development alliances. Journal of Product Innovation Management, 20(6), 468-484.

Dierickx, I., \& Cool, K. (1989). Asset stock accumulation and sustainability of competitive advantage. Management Science, 35(December), 1504-1511. 
Dwyer, F. R., Schurr, P. H., \& Oh, S. (1987). Developing Buyer-Seller Relationships. Journal of Marketing, 51(April), 11-27.

Fichman, M., \& Levinthal, D. A. (1991). Honeymoons and the liability of adolescence: A new perspective on duration dependence in social and organizational relationships. Academy of Management Review, 16(2), 442-468.

Finn, A., \& Kayande, U. (2005). How fine is C-OAR-SE? A generalizability theory perspective on Rossiter's procedure. International Journal of Research in Marketing, 22(1), 11-21.

Ford, D. (1980). The Development of Buyer-Seller Relationships in Industrial Markets. European Journal of Marketing, 14(5/6), 339 - 353. doi:10.1108/EUM0000000004910

Ford, D. (1990). Understanding Business Markets: Interaction, Relationships and Networks. London: Academic Press.

Geertz, C. (1973). Thick description: Toward an interpretive theory of culture. In The interpretation of cultures: Selected essays (pp. 3-30). New York: Basic Books.

Gladwell, M. (1996). The tipping point: Why is the city suddenly so much safer - could it be that crime really is an epidemic? The New Yorker, 72(14), 32-38.

Granovetter, M. (1985). Economic action and social structure: The problem of embeddedness. The American Journal of Sociology, 91(3), 481-510.

Gulati, R. (1995). Social structure and alliance formation patterns: A longitudinal analysis. Administrative Science Quarterly, 40(4), 619-652.

Gouldner, A. W. (1960). The Norm of Reciprocity: A Preliminary Statement. American Sociological Review, 25(2), 161-178.

Gulati, R., \& Gargiulo, M. (1999). Where do interorganizational networks come from? American Journal of Sociology, 104(5), 1439-1493. 
Håkansson, H. (Ed.). (1982). International marketing and purchasing of industrial goods: An interaction approach. Chichester: John Wiley and Sons.

Håkansson, H., \& Snehota, I. (Eds.). (1995). Developing Relationships in Business Networks. London: Routledge.

Han, S.-L. (1991). Antecedents of buyer-seller long-term relationships: An exploratory model of structural bonding and social bonding. Unpublished Doctoral Dissertation, Pennsylvania State University, University Park: PA.

Han, S.-L., \& Wilson, D. T. (1993). Antecedents of buyer commitment to a supplier: A model of structural bonding and social bonding. Unpublished paper, Marketing Department, Pennsylvania State University.

Harman, H. H. (1976). Modern factor analysis (3 ed.). Chicago: The University of Chicago Press.

Heugens, P., \& Zyglidopoulos, S. (2008). From social ties to embedded competencies: The case of business groups. Journal of Management \& Governance, 12(4), 325-341.

Hofer, C. W., \& Schendel, D. (1978). Strategy formulation: Analytical concepts. St. Paul, MN: West Publishing Company.

Homans, G. C. (1958). Social behavior as exchange. The American Journal of Sociology, 63(6), 597-606.

Homans, G. C. (1961). Social behaviour: Its elementary forms. London: Routledge and Kegan Paul.

Hunt, S. D. (1991). Modern marketing theory: Critical issues in the philosophy of marketing science. Cincinnati, OH: South-Western Publishing Co.

Hunt, S. D., \& Morgan, R. M. (1995). The comparative advantage theory of competition. Journal of Marketing, 59(2), 1-15. 
Kelley, H. H., \& Thibaut, J. W. (1978). Interpersonal Relations: A Theory of Interdependence. New York: Wiley.

Kimberly, J. R. (1979). Issues in the creation of organizations: Initiation, innovation, and institutionalization. Academy of Management Journal, 22(3), 437-457.

Kriauciunas, A., \& Kale, P. (2006). The impact of socialist imprinting and search on resource change: A study of firms in Lithuania. Strategic Management Journal, 27(7), 659679.

Kriauciunas, A., \& Shinkle, G. (2008). Organizational imprinting: Informing firm behavior in domestic and international contexts. Purdue University.

Macneil, I. R. (1980). The New Social Contract. New Haven, CT: Yale University Press.

McClelland, D. C. (1998). Identifying competencies with behavioral-event interviews. Psychological Science, 9(5), 331.

Meade, J. E. (1952). External economies and diseconomies in a competitive situation. The Economic Journal, 62(245), 54-67.

Morgan, R. M., \& Hunt, S. D. (1999). Relationship-Based Competitive Advantage: The Role of Relationship Marketing in Marketing Strategy. Journal of Business Research, 46, 281-290.

Mummalaneni, V., \& Wilson, D. T. (1991). The influence of a close personal relationship between a buyer and seller on the continued stability of their role relationship, Working paper 4-1991: The Institute for the Study of Business Markets, Pennsylvania State University.

Palmatier, R. W., Dant, R. P., \& Grewal, D. (2007). A Comparative Longitudinal Analysis of Theoretical Perspectives of Interorganizational Relationship Performance. Journal of Marketing, 71(4), 172-194. 
Palmatier, R. W., Gopalakrishna, S., \& Houston, M. B. (2006). Returns on Business-toBusiness Relationship Marketing Investments: Strategies for Leveraging Profits. Marketing Science, 25(5), 477-493.

Palmatier, R. W., Scheer, L. K., Houston, M. B., Evans, K. R., \& Gopalakrishna, S. (2007). Use of relationship marketing programs in building customer-salesperson and customer-firm relationships: Differential influences on financial outcomes. International Journal of Research in Marketing, 24(3), 210-223. doi:10.1016/j.ijresmar.2006.12.006

Pedhazer, E. J. (1997). Multiple regression in behavioral research. Fort Worth, TX: Harcourt Brace.

Peter, J. P. (1981). Construct validity: A review of basic issues and marketing practices. Journal of Marketing Research, 18(2), 133-145.

Pfeffer, J., \& Salancik, G. (1978). The external control of organizations: A resource dependence perspective. New York: Harper and Row.

Podsakoff, P. M., MacKenzie, S. B., Lee, J.-Y., \& Podsakoff, N. P. (2003). Common Method Biases in Behavioral Research: A Critical Review of the Literature and Recommended Remedies. Journal of Applied Psychology, 88(5), 879.

Porter, M. E. (1985). Competitive advantage: Creating and sustaining superior performance. New York: Free Press.

Prahalad, C. K., \& Hamel, G. (1990). The core competence of the corporation. Harvard Business Review, 68(May/June), 79-91.

Rodríguez, C. M., \& Wilson, D. T. (2002). Relationship bonding and trust as a foundation for commitment in U.S.-Mexican strategic alliances: A structural equation modeling approach. Journal of International Marketing, 10(4), 53-76. 
Rossiter, J. R. (2002). The C-OAR-SE procedure for scale development in marketing. International Journal of Research in Marketing, 19(4), 305.

Schein, E. H. (1983). The role of the founder in creating organizational culture. Organizational Dynamics, 12(1), 13-28.

Schiele, H., Calvi, R., \& Gibbert, M. (2012). Customer attractiveness, supplier satisfaction and preferred customer status: Introduction, definitions and an overarching framework. Industrial Marketing Management, 41(8), 1178-1185. doi:http://dx.doi.org/10.1016/j.indmarman.2012.10.002

Seabright, M. A., Levinthal, D. A., \& Fichman, M. (1992). Role of Individual Attachments in the Dissolution of Interorganizational Relationships. Academy of Management Journal, 35(1), 122-160.

Stinchcombe, A. (1965). Social structure and organizations. In J. G. March (Ed.), Handbook of organizations (pp. 142-193). Chicago: Rand McNally.

Turnbull, P. W., \& Wilson, D. T. (1989). Developing and protecting profitable customer relationships. Industrial Marketing Management, 18(3), 233-238. doi:Doi: $10.1016 / 0019-8501(89) 90040-0$

Uzzi, B. (1999). Embeddedness in the making of financial capital: How social relations and networks benefit firms seeking financing. American Sociological Review, 64(4), 481505.

Varey, R. J. (2008). Marketing as an Interaction System. Australasian Marketing Journal, 16(1), 79-94.

Vargo, S. L., \& Lusch, R. F. (2004). Evolving to a New Dominant Logic for Marketing. Journal of Marketing, 68(1), 1-17. 
Walter, A., Hölzle, K., \& Ritter, T. (2002). Relationship functions and customer trust as value creators in relationships: A conceptual model and empirical findings for the creation of customer value. Paper presented at the 18th IMP-conference. From http://www.impgroup.org/uploads/papers/554.pdf

Wernerfelt, B. (1984). A resource-based theory of the firm. Strategic Management Journal, $5,171-180$.

Williamson, O. E. (1975). Markets and Hierarchies: Analysis and Antitrust Implications. New York: Free Press.

Williamson, O. E. (1984). Credible Commitments: Further Remarks. The American Economic Review, 74(3), 488-490.

Wilson, D. T. (1995). An integrated model of buyer-seller relationships. Journal of the Academy of Marketing Science, 23(4), 335-345.

Wilson, D. T., \& Jantrania, S. (1994). Understanding the value of a relationship. AsiaAustralia Marketing Journal, 2(1), 55-66.

Wilson, D. T., \& Mummalaneni, V. (1986). Bonding and commitment in supplier relationship: A preliminary conceptualization. Industrial Marketing and Purchasing, 1(3), 44-58. 


\section{APPENDIX}

\section{A. Instructions for the Resource Allocation Scale Items}

“Please consider your firm's relationship with your chosen customer at present. How high is your organization's level of input of the following resources into the relationship, compared with your other customers?" (1 - 7 scales from "Very much lower" to "Very much higher")

- Dollars your firm puts into the relationship

- Physical items such as equipment your firm puts into the relationship

- The amount of time that your personnel spend working on the relationship

- Your intangible inputs, such as knowledge, skills, ingenuity, and your business contacts (KSIB)

\section{B. Instructions for the Relationship Bonding Scale Items}

"How much do you agree with the following statements about your firm's relationship with the chosen customer, as compared with other customers?" (1 - 7 scales from "I do not agree at all" to "I fully agree")

- We have strong social bonds with people in the customer organization

- The relationship is very profitable for us

- Our firm shares a lot of goals with this customer 
Panel A:

Honeymoon Model

Social Bond

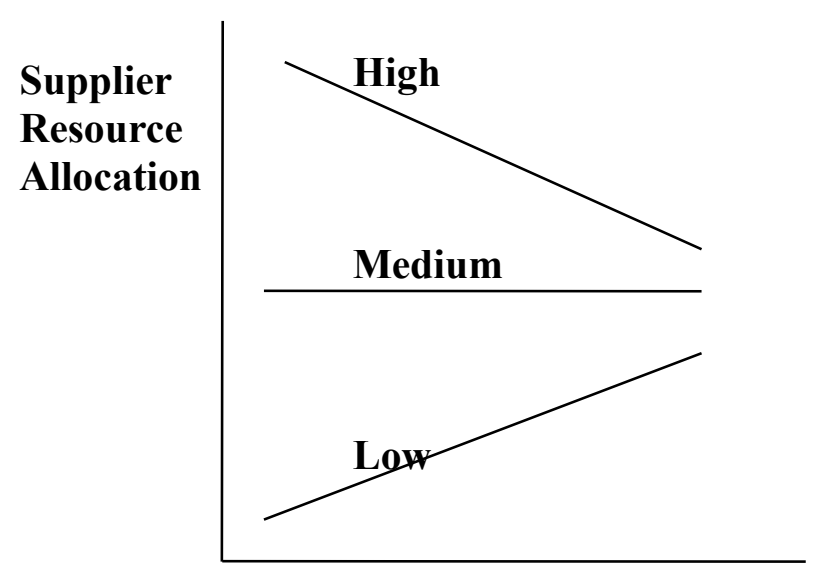

Years in relationship
Panel B:

Maturity Model

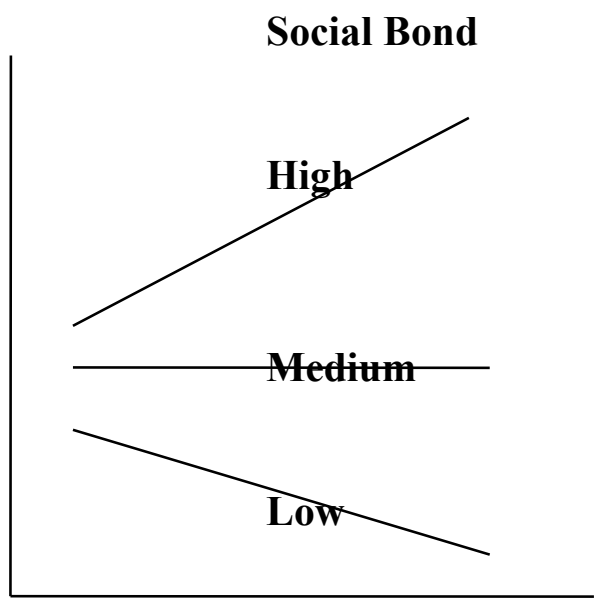

Years in relationship
Panel C:

Imprinting Model

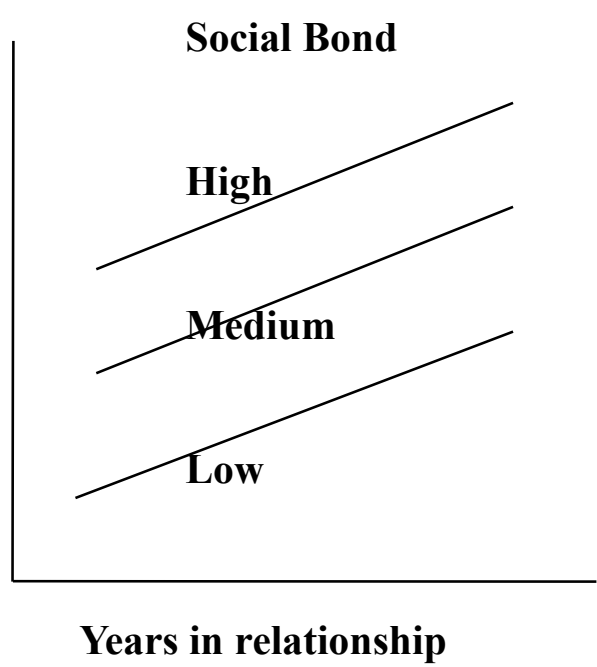

Figure 1

Three Models of How Social Bonding Affects Supplier Allocation of Resources 
Table 1

Resource Allocations by Supplier to Customers with Low, Medium, and High Social Bonds with the Supplier by Years in the Relationship

\begin{tabular}{|c|c|c|c|c|c|c|c|c|c|c|}
\hline \multirow{2}{*}{$\begin{array}{c}\text { Social } \\
\text { Bonding }\end{array}$} & \multirow{3}{*}{$\begin{array}{c}\text { Years in } \\
\text { Relationship }\end{array}$} & \multicolumn{9}{|c|}{ Resource } \\
\hline & & \multicolumn{2}{|c|}{ Dollars } & \multicolumn{2}{|c|}{ Physical Items } & \multicolumn{2}{|c|}{ Time } & \multicolumn{3}{|c|}{ Intangibles (KSIB) } \\
\hline & & M & s.e. & M & s.e. & $\mathbf{M}$ & s.e. & M & s.e. & $\mathbf{n}$ \\
\hline \multirow[t]{6}{*}{ Low } & $1-5$ & 3.50 & .19 & 3.69 & .27 & 4.58 & .22 & 4.85 & .25 & 26 \\
\hline & $6-8$ & 4.00 & .21 & 3.94 & .30 & 4.65 & .31 & 5.29 & .21 & 17 \\
\hline & $9-10$ & 3.63 & .33 & 3.38 & .30 & 4.56 & .24 & 5.06 & .27 & 16 \\
\hline & $11-16$ & 4.38 & .31 & 3.62 & .49 & 5.12 & .25 & 5.08 & .24 & 13 \\
\hline & $17+$ & 4.00 & .28 & 3.85 & .24 & 4.50 & .26 & 4.70 & .19 & 20 \\
\hline & Total & 3.85 & .19 & 3.70 & .14 & 4.65 & .11 & 4.97 & .11 & 92 \\
\hline \multirow[t]{6}{*}{ Medium } & $1-5$ & 4.63 & .34 & 3.37 & .36 & 4.89 & .33 & 4.95 & .28 & 19 \\
\hline & $6-8$ & 4.11 & .28 & 3.64 & .31 & 4.86 & .18 & 4.86 & .18 & 28 \\
\hline & $9-10$ & 4.20 & .28 & 3.96 & .31 & 4.92 & .23 & 5.40 & .21 & 25 \\
\hline & $11-16$ & 4.43 & .30 & 3.48 & .29 & 4.78 & .25 & 5.30 & .23 & 23 \\
\hline & $17+$ & 4.47 & .19 & 3.73 & .21 & 5.13 & .16 & 5.37 & .17 & 30 \\
\hline & Total & 4.35 & .12 & 3.65 & .13 & 4.93 & .10 & 5.18 & .09 & 125 \\
\hline \multirow[t]{6}{*}{ High } & $1-5$ & 4.12 & .27 & 3.52 & .30 & 4.96 & 1.06 & 5.52 & .15 & 25 \\
\hline & $6-8$ & 5.11 & .28 & 4.32 & .41 & 5.42 & 1.39 & 5.84 & .21 & 19 \\
\hline & $9-10$ & 4.43 & .31 & 4.57 & .33 & 5.14 & .66 & 5.79 & .24 & 14 \\
\hline & $11-16$ & 4.35 & .24 & 4.17 & .33 & 5.57 & .95 & 5.70 & .21 & 23 \\
\hline & $17+$ & 5.25 & .23 & 4.56 & .37 & 5.38 & .81 & 5.63 & .26 & 16 \\
\hline & Total & 4.60 & .13 & 4.15 & .16 & 5.30 & 1.03 & 5.68 & .09 & 97 \\
\hline \multicolumn{2}{|l|}{ F-value } & \multicolumn{2}{|c|}{8.67} & \multicolumn{2}{|c|}{3.67} & \multicolumn{2}{|c|}{8.32} & \multicolumn{2}{|c|}{12.93} & \\
\hline \multicolumn{2}{|c|}{$\mathrm{DF}=2 / 331(\mathrm{p}<)$} & \multicolumn{2}{|c|}{ (.000) } & \multicolumn{2}{|c|}{ (.027) } & \multicolumn{2}{|c|}{ (.000) } & \multicolumn{2}{|c|}{ (.000) } & \\
\hline \multicolumn{2}{|l|}{$\eta^{2} \quad\left(\mathbf{E t a}^{2}\right)$} & \multicolumn{2}{|c|}{.053} & \multicolumn{2}{|c|}{.023} & \multicolumn{2}{|c|}{.051} & \multicolumn{2}{|c|}{.077} & \\
\hline
\end{tabular}




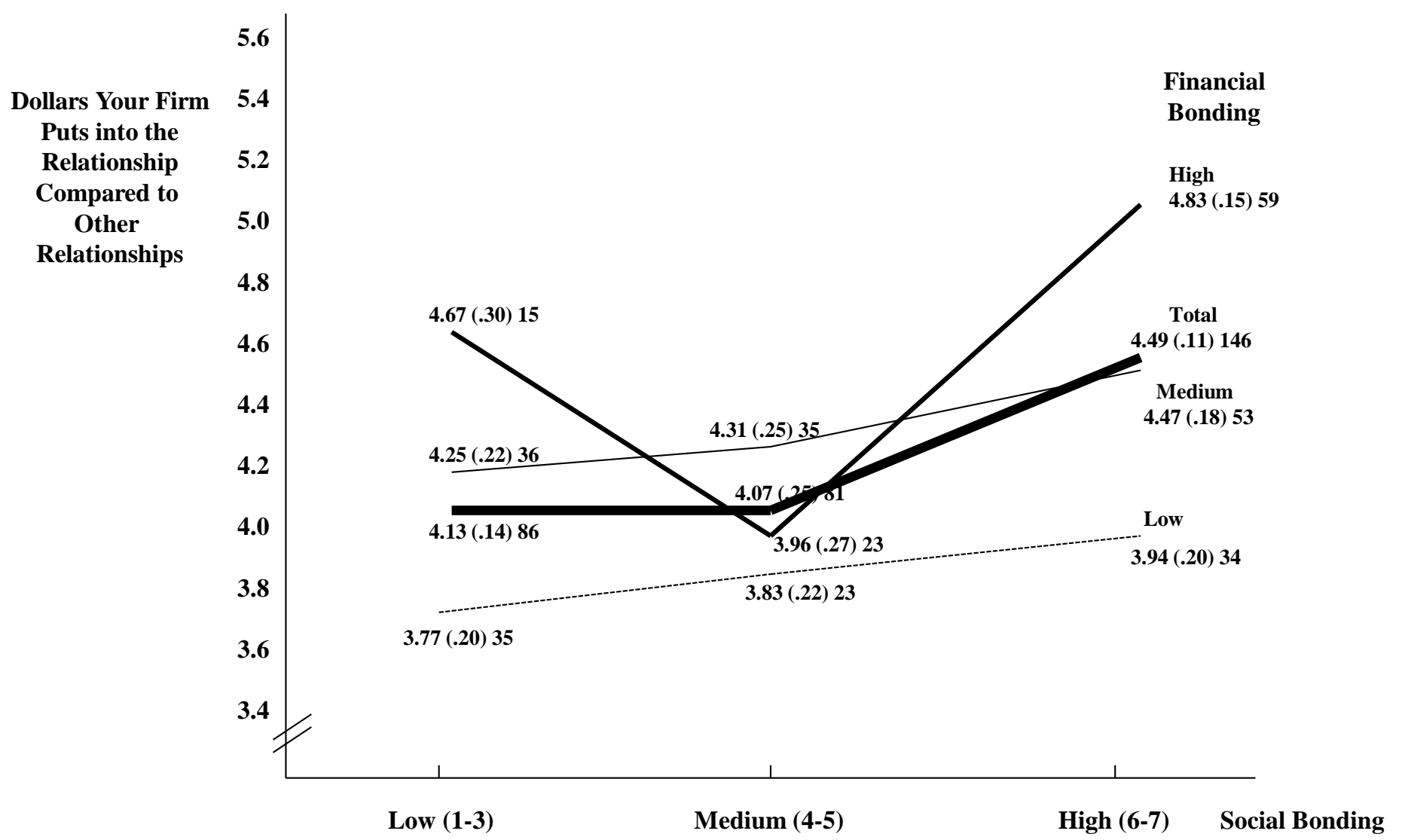

Figure 2

Social Bonding Influence on Supplier Allocation of Dollar Resources, Controlling for Financial Bonding Note. Numbers include the mean (standard error) sample size. $F=8.74, D F=2 / 310, p<.000 ; \eta^{2}=.053$ ). 
Table 2

Relationships of Four Resource Allocations, Social, and Financial Bonding Variables:

Double-Headed Arrows Show Bivariate Correlations of Resources with Social Bonding above the Diagonal and Partial Correlations of Resources with Social Bonding Controlling for Financial Bonding below the Diagonal

\section{Variable}

1. Dollar your firm puts into the relationship

2. Physical items such as equipment...

3. Time that firm's personnel spend working...

4. Your intangible inputs, such as knowledge, ...

5. Social: We have strong social bonds with people... ${ }^{\mathrm{c}}$

6. Financial: This relationship is very profitable for us ${ }^{d}$

7. Years: For how many years has your firm ...

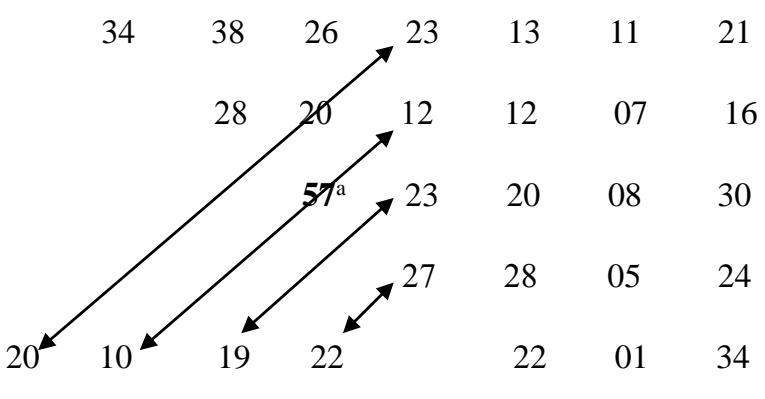

$09 \quad 10 \quad 15 \quad 23$

8. Validation item: "Our firm shares a lot of goals with this customer" e

Note. Decimals omitted; $r>.10, p<.05 ; r>.18, p<.01$

${ }^{\mathrm{a}}$ Highest correlation $(\mathrm{r}=.57)$ indicates that high intangible inputs into a relationship take a lot of time resources.

b Years of relationship has significant relationship with only one resource, dollars; finding is suggestive that more versus less profitable relationships survive for longer periods.

${ }^{c}$ Partial correlations of resources with social bonding controlling for financial bonding.

d Partial correlations of resources with financial bonding controlling for social bonding.

e Validation correlations matches pattern correlation predictions: highest for two bonding variables and nonsignificantly with years. 
Table 3

Four Resource Allocations, Social, and Financial Bonding Variables Corrected for Common Method Variance:

Double-Headed Arrows Show Bivariate Correlations of Resources with Social Bonding above the Diagonal and Partial Correlations of Resources with Social Bonding Controlling for Financial Bonding below the Diagonal

\section{Variable}

1. Dollar your firm puts into the relationship

2. Physical items such as equipment...

3. Time that firm's personnel spend working...

4. Your intangible inputs, such as knowledge, ...

5. Social: We have strong social bonds with people...

6. Financial: This relationship is very profitable for us ${ }^{d}$

7. Years: For how many years has your firm ...

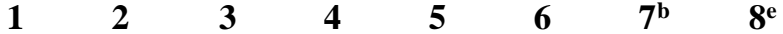

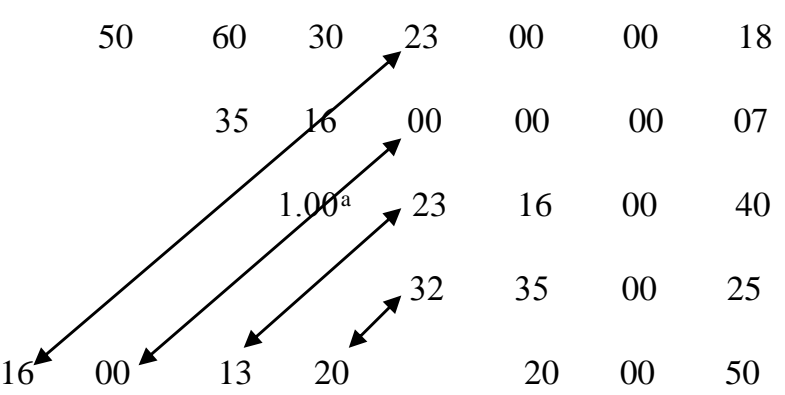

$00 \quad 00 \quad 05 \quad 23$

8. Validation item: "Our firm shares a lot of goals with this customer" e

Note. Decimals omitted; $\mathrm{r}>.10, \mathrm{p}<.05 ; \mathrm{r}>.18, \mathrm{p}<.01$

${ }^{a}$ Highest correlation (original $\mathrm{r}=.57$ ) indicates that high intangible inputs into a relationship take a lot of time resources.

${ }^{b}$ Years of relationship has significant relationship with only one resource, dollars; finding is suggestive that more versus less profitable relationships survive for longer periods.

c Partial correlations of resources with social bonding controlling for financial bonding.

${ }^{\mathrm{d}}$ Partial correlations of resources with financial bonding controlling for social bonding.

e Validation correlations matches pattern correlation predictions: highest for two bonding variables and nonsignificantly with years. 


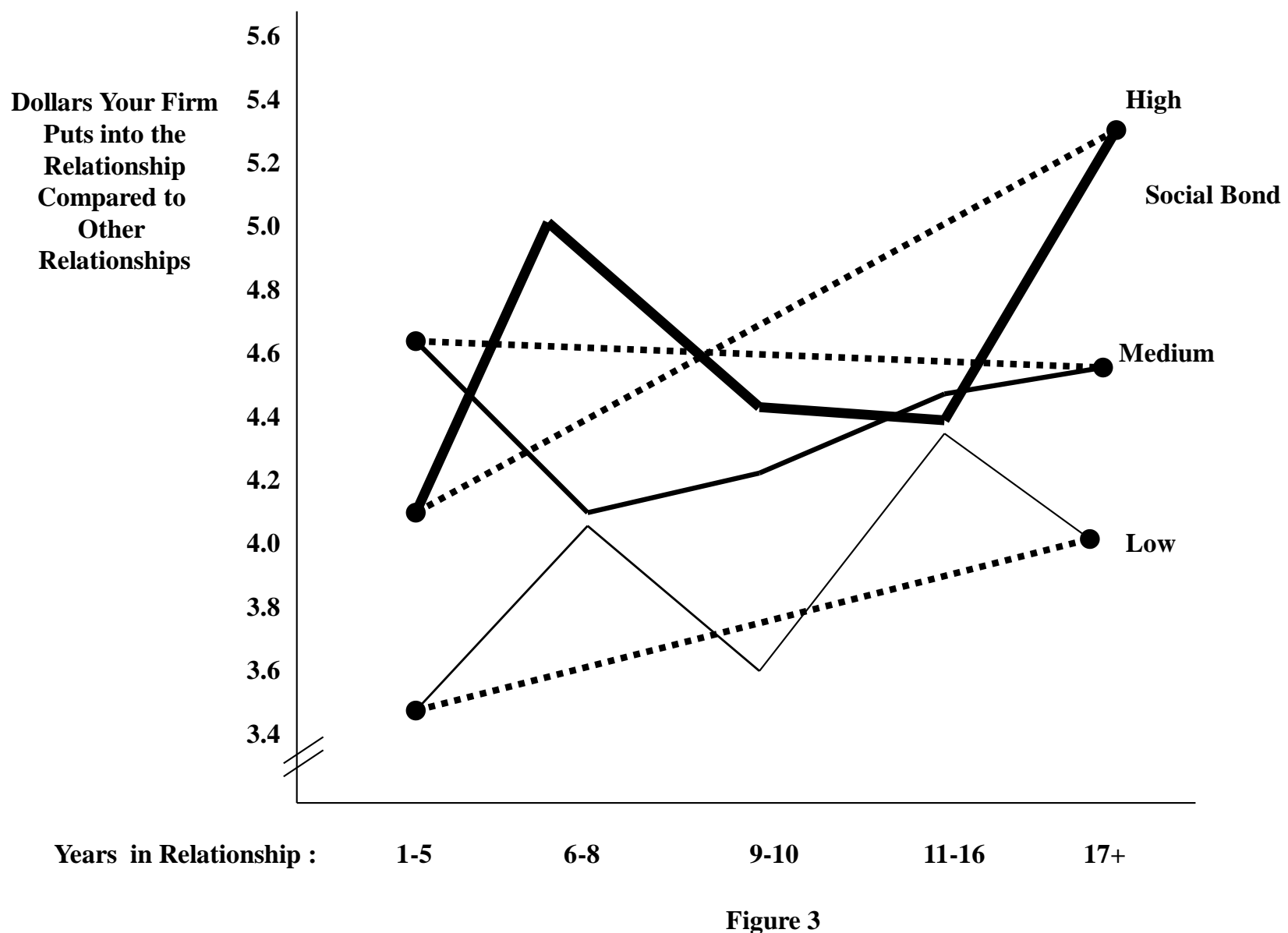

Influence of Years in Relationship on Dollars Supplier Puts into the Relationship for Three Levels of Social Bonding

Note. Dotted line indicates a modest positive interaction effect of social bonding and length of the relationship on dollars supply firm puts into the relationship. The findings support the imprinting theory of social bonding influence on dollar resource allocation by suppliers. 


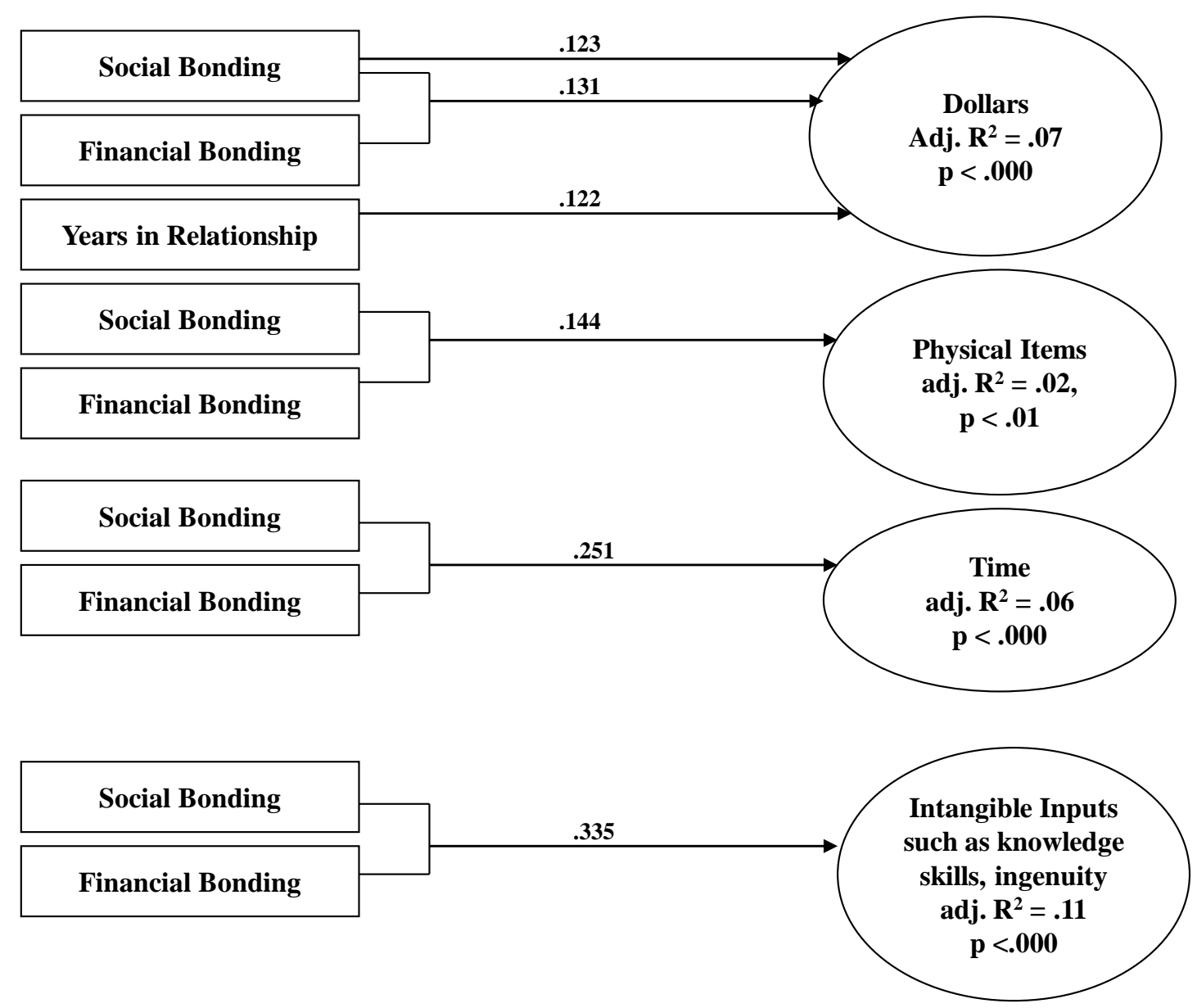

Figure 4

Path Models of Social Bonding, Financial Bonding, and Years in Relationship Predicting Resource Allocations Numbers on Arrows are betas, $\beta$ (standardized partial regression coefficients) 
